\title{
THE HISTOLOGY OF THE NASAL MUCOUS MEMBRANE OF THE PIG'
}

\author{
NATHANIEL ALCOCK \\ From the Zoölogical Laboratory of Northwestern University \\ WITH FIFTEEN FIGURES
}

With the introduction of the methylene blue and the Golgi methods there began a new era of investigating nervous tissues. When these methods were applied to the histology of the nasal mucous membrane, they made clear for the first time the connection of undoubted olfactory fibers with the sensory cells. Prior to the use of these methods a number of interesting observations on the structure of the nasal epithelium had been madeextending, in fact, over a period of thirty years-but the results obtained have been largely superseded by later investigations.

The pioneer group of researches upon the nasal mucous membrane includes the work of Eckhard ('55), Ecker ('55), Max Schultze ('56, '62), Exner ('72), Cisoff ('74), and von Brunn ('75, '80).

The papers of this period worthy of greatest consideration are those of Max Schultze. In $1856^{2}$ he made the first good analysis of the histology of the nasal mucous membrane, observing all classes of vertebrates and giving sketches of two kinds of cells in the pike, frog, owl and man. His figures were so good that two of them (of frog and man) have been frequently republished.

The two kinds of cells that he designated are (a) six-sided prismatic supporting elements-non-ciliated in the olfactory region, but ciliated in the respiratory region, and $(b)$ true olfactory cells with a large body, a slender peripheral process, and very fine central process showing varicosities. He was the first to claim that the olfactory cells were the only percipient elements of the sense of smell. He supposed their central

\footnotetext{
${ }^{1}$ Contribution from the Zoölogical Laboratory of Northwestern University under the direction of William $A$. Locy.

'Monatsber. d. K. Preuss. Akad. d. Wiss. zu Berlin, November, 1856. Pp. 504-514.
} 
fibers were the true olfactory fibers but was unable to trace them to the olfactory bulb. He found olfactory hairs on the sensory cells of the frog but not on those of mammals. He also saw stellate cells which he likened to the ganglionic cells of the retina. His paper of $1862^{3}$ of ninetyfour pages and five lithographed plates is an extension of his earlier observations and embraces observations on all classes of vertebrates.

It was in 1886 that Ehrlich published his paper on the methylene blue method and described its reaction toward several types of nerve-cells, among them the olfactory sensory-cells. He described these briefly, paying special attention to the central processes of the cells which he observed passing downwards between the central processes of tine supporting cells into the submucosa and there being continued as the small fibers of the olfactory nerve. This was an ocular demonstration of the connection that Max Schultze had assumed to exist. The following ycar Arnstein, employing the same method, published a paper in which hedescribed the connection of the olfactory cells with the olfactory nerve and thus agreed with Ehrlich.

In $1887,{ }^{4}$ Dogiel published the results of his work on the olfactory organ of ganoids, teleosts, and amphibians. His observations indicate a polymorphism of sensory cells of the olfactory membrane. He described three types which have been seen by several other observers (Morrill, '98; Jagodowski, '01).

The observations of Grassi and Castronovo ${ }^{5}$ in 1889 by the application of the Golgi method to the olfactory membrane of the dog, strengthened the conclusion that the fibers of the olfactory nerve are connected directly with the nerve-cells of the olfactory membrane. They described the true olfactory cell and also a fine varicose central process descending in a curved course to the subepithelium and there uniting with similar fibers to form the olfactory nerve. They also mentioned free nerve endings in the nasal mucous nembrane. They observed no anastomosis of nerve processes although they did show in their figures and described in their text one case where two sensory cells were connected by one fiber. They held that the supporting cells were not connected with the nerve fibers. They described the histology of the three areas of the olfactory membrane, giving particular attention to the boundary or intermediate zone, concluding that in the adult it exhibited the embryonic characteristics of the true olfactory region.

${ }^{3}$ Arch. f. Mik. Anat. Bd. 27, 1886.

4 Abhandl. d. Naturf. Gesellsch. zu Halle. Bd. 7.

${ }^{s}$ Arch. f. Mik. Anat. Bd. 34, 1889. Pp. 385-390. 
It will be noted that up to this time investigators had generally supposed that the direction of growth of olfactory nerve fibers was outward from the brain to the olfactory membrane. In the year 1889 this conception was materially changed through the work of William His on the development of nerve fibers and also through that of Ramon $y$ Cajal. The latter traced fibers of the olfactory nerve to the bulbus olfactorius and there found them terminating in brush-like ends that commingle with the dendrites of the mitral cells and form the olfactory glomeruli. He concluded therefore that the sensory cells in the olfactory membrane are the cell bodies from which fibers of the olfactory nerve arise, and that the fibers of this nerve grow not from the brain to the membrane, but the reverse.

The occurrence of free nerve endings in the olfactory membrane was indicated by Cajal. He gives a sketch showing free nerve endings between the cells of the olfactory membrane. Von Lenhossék observed similar appearances and concluded that they were terminations of the trigeminal nerve.

The work of Van Gehuchten ('90) on the rabbit and that of Retzius ('92) on embryos of the mouse, cat, dog and rabbit and his further paper in 1894 on the fishes confirmed the work of previous investigators, adding certain details that do not require mention here.

Von Brunn's paper of $1892^{6}$ dealing with the nasal membrane of the human body is of especial interest. This observer had published two previous papers on the anatomy of the olfactory apparatus, one in 1875 (Dog, Cat, Rabbit, Sheep, Calf, Fish, Salamander) and another, in 1880 (Rabhit) on the same organ in the rabbit. The third paper (1892) dealt with the olfactory apparatus of man. He gives a complete analysis of the membrane, describing its extent, the different cells found, the limiting membrane (described in the three papers, but first mentioned by Sidky), the nasal cells and the connection of the nerve and the sensory element. On the peripheral ends of the olfactory cells he observed from six to eight short pointed hairs but was unable to say whether or not these were normal structures or artefacts. However, he thought them to be normal structures. He concluded also that the nerve fibers are in connection with the sensory-cells only, and not with the supporting elements.

Jagodowski $\mathrm{i}^{7}$ in 1901 , published observations on the olfactory organ

${ }^{6}$ Arch. f. Mik. Anat. Bd. 29, 1887.

'Anat. Anz. Bd. 19, 1901. 
of the pike. He described three types of sensory elements corresponding to those mentioned by Dogiel. The types are $(a)$ cylindrical Riechzellen of Max Schultze with slender peripheral processes, (b) Riechstäbchen. with peripheral processes as thick as the cell-body, and (c) Riechzapfen, short cells, near the outer border of the mucosa and lacking a peripheral process. This polymorphic condition of olfactory cells has been observed by Morrill ('98, Selachians) and Grassi and Castronovo have pictured a cell like the Zapfen in the olfactory membrane of the dog. He also described a new structure, the smell whips. According to Jagodowski each type of olfactory cell bears on the peripheral end a long slender whip-like process which extends into the nasal cavity. He also saw free nerve endings.

Ballowitz ${ }^{8}$, in 1904, published observations on Petromyzon fluviatlis, which corroborated the work of Retzius (1880), also on petromyzon. He found but one kind of sensory elements and no transitional forms. According to his observations the olfactory cells are of one type but vary in length according to the position of their nuclei in the membrane. On their peripheral ends he saw 10 to 12 fine pointed hairs which are beautifully represented in his sketches. He observed cilia on the supporting cells.

Work on the development of the nervous elements of the olfactory membrane, such as that of Disse ('96) and Bedford ${ }^{10}$ ('04), shows conclusively that the neuroblasts of the olfactory nerve fibers are located within the membrane, and that the nerve fibers grow from the nerve cells toward the brain.

Miss Read's" "Contribution to the Knowledge of the Olfactory Apparatus in Dog, Cat and Man" ('08), embraces the study of the gross anatomy of the olfactory nerve, as well as a description of the histological structure of the olfactory epithelium illustrated by many figures. Her work also includes a study of the organon vomero-nasale. Her sketches of the sensory-cells of the cat, stained with methylene blue, show the character of these cells very well. She found free nerve terminations in the olfactory membrane, which she regards as derivatives of the trigeminal nerve. She determined that there is no anastomosis of the nerve fibers, but that they preserve their individuality from the nasal epithelium until they terminate in the glomeruli of the

${ }^{8}$ Arch. f. Mik. Anat. Bd.64, 1904.

'Marburg. Sitzungsbr., October, 1896.

${ }^{10}$ Jour. Comp. Neurol. and Psychol., vol. xiv, 1904.

${ }^{11}$ Am. Jour. Anat. May, 1908. 
olfactory bulb. She finds in the epithelium of the organon vomeronasale cells apparently identical with the sensory-cells of the olfactory mucosa.

More extended reviews of literature are found in Disse (Ergeb. $d$. Anat. u. Entwickl., Bd. 11, 1901), Jagodowski (Anat. Anz., 1901), and Miss Read (Am. Jour. Anat., May, 1908). The last mentioned paper was not available until I had completed my work.

\section{OBSERVATIONS}

The observations, the results of which follow, were undertaken with a view to supplying a purely objective account of the form of the various cellular elements entering into the composition of the nasal mucous membrane, and to determine their normal arrangement. The work was begun in September, 1906, in the Zoölogical Laboratory of Northwestern University, and was carried on for two years. From the beginning it has been under the direction of Prof. William A. Locy, whom I wish to thank for assistance in the observations and preparation of the manuscript. Observations were begun on the rabbit, but by comparison the nasal mucous membrane of the pig was found to give better pictures of the cellular elements, and the present account is confined to descriptions of pig material. I also had for comparison a large series of sections of the nasal-mucous membrane of the rabbit made by Miss Caroline Jaycox.

The pig material used consisted of embryos from six to twelve inches long obtained from the uterus of the parent about thirty minutes after the latter had been killed. In all cases the young specimens were found alive and in good condition. After removal from the uterus the head of the embryo was severed from the body, and split into halves. The nasal cavity was opened by cutting away the septum, and either the whole placed in the fixing or macerating fluid or the turbinal bones removed and placed in the desired liquid.

Two general methods have been followed: That of maceration and that of the study of sections.

Several of the standard macerating fluids were employed. It was found, however, that 25 per cent to 30 per cent alcohol gave 
good results with this material. The pieces of tissue were placed in the liquid for a period of thirty-six to forty-eight hours and in a few cases good results were obtained from material which had remained in the alcohol from seventy-two to ninety-six hours. The length of time necessary varies with the age of the pig. The pieces were then transferred whole to a solution of equal parts of 50 per cent alcohol and glycerine in which they were first teased with needles and then shaken vigorously in small bottles. In the majority of cases the cells were found floating free and in clusters in the liquid. To the solution containing the isolated cells were added a few drops of picro-carmine which, in a few hours, stained the cells very satisfactorily. A few drops of this material was then mounted and the coverslip sealed with glycerine jelly and gold-size cement.

For fixing fluids Van Gehuchten's, Müller's, 5 per cent formalin, formalin-acetic, corrosive-acetic, picro-sulphuric, and Zenker's were used. The best results came from the fixation by the Zenker solution. For relatively thick sections the pieces of material were imbedded in celloidin and for thinner sections paraffin was used. The most common and best stains used were iron alum and hæmatoxylin, and eosin and Delafield's hæmatoxylin. The sections range from three to eight microns in thickness.

The larger celloidin sections, after imbedding, were decalcified in 5 per cent nitric acid for twenty-four hours.

In the pig there are five chief ethmo turbinal folds each of which is lobulated. The arrangement exhibited in Fig. 1, which is a drawing of a section cut in a plane perpendicular to the long axis of these folds of a pig embryo twelve inches long, is as follows: The five main folds $(\mathrm{F} 1,2,3,4,5)$ each have a cartilage supporting tissue covered with a relatively thick epithelium. Each fold, with the exception of the second, extends to the side wall of the cavity. The lateral surfaces of the several main folds are elevated into ridges which run horizontally. The first main fold shows 12 of these ridges. The second, which seems to be a division of the first, 8 ; the third, 11; the fourth, 7 ; the fifth, 4 . Between the second and third main folds are two smaller ones ( $\mathrm{F} 6$ and 7 ); between the third and fourth and between the fourth and fifth are also seen smaller folds $(F-9)$. 
In fresh material of the stages examined the epithelium of the nasal cavity is apparently of uniform color. It was not possible to distinguish areas of a yellowish tint indicating the distribution of the olfactory cells, as has been observed in many vertebrates.

The epithelium in fresh condition is so tender that it is almost impossible to remove it from the cartilage upon which it lies, but after fixation with Zenker's fluid this can easily be done even from the turbinal folds. However, it was found that the epithelium of these folds could best be sectioned by leaving it attached to the cartilage and dividing the entire piece into six to eight blocks.

As there is no easily discernible color variation in the different parts of the nasal mucous membrane of pigs of this age, the different areas can be distinguished only by a study of their finer anatomy. On the basis of the thickness of the epithelium and of its component elements two regions can easily be distinguished. One, designated by the earlier investigators as the respiratory region, includes the epithelium of the outer side, the upper, and the lower walls of the nasal cavity and certain parts of the turbinal folds and of the septum. The second, the olfactory region, embraces the sensory epithelium found on the turbinal folds and parts of the septum. My study of its structure was limited to that part on the ethmo-turbinal folds. A third area, the intermediate zone, described at length by Grassi and Castronovo in the $\mathrm{dog}$, can be distinguished in the pig.

Respiratory Region. The epithelium of the respiratory region (Fig. 2) is from .037 to $.041 \mathrm{~mm}$. in thickness, It is composed of two kinds of cells, cylindrical epithelial cells (Sup. C.) and the basal cells (Bas. C.). The cylindrical cells (see also Fig. 3 ) extend across the epithelium from the frce surface to the basement membrane. Their large oval nuclei lie a little above the middle horizontal plane of the section. The majority of them show a large oval nucleolus. The peripheral process of each cell extends to the surface where it expands slightly into a dome-shaped dise above the limiting membrane. On this disc are found fifteen to twenty-five slender hairs ( $C i l$.) which average about $.0065 \mathrm{~mm}$. in length. The central process (Cen. Pr.) of each cylindrical 
cell extends from the region of the nucleus almost to a pointed end which rests on the basement membrane. These cells show no branching or forking. In the spaces between the pointed ends are the basal cells (Bas. C.) which are conical in shape with their large bases turned toward the basement membrane. The nuclei of the latter are spherical.

The sub-mucosa of this respiratory region is from two to three times the thickness of the epithelium itself. It is made up of loose elastic connective tissue and in it are to be seen numerous blood vessels and many of Bowman's glands.

Olfactory Region. (a) The Supporting Elements. The olfactory membrane, containing the sensory nervous elements, is confined to the epithelium of the turbinal folds. It has been found on all five of the folds, both on the surface exposed to the nasal cavity and on the lateral surfaces as well. The sensory olfactory membrane varies in thickness from .062 to $.07 \mathrm{~mm}$. It is composed of three types of cellular elements, namely, two kinds of supporting elements and the sensory cells. The supporting elements are the cylindrical cells (Figs. 4,10, 11,12) and the basal cells (Fig. 12, Bas. C.) The latter are similar to those found in the respiratory region. The cylindrical cells are different from those of the respiratory area. Their nuclei which, like those already described, are large and oval, lie in a plane near the limiting membrane, relatively higher in position than those of the supporting cells of the respiratory region. These nuclei stain very deeply with iron hæmatoxylin and also with hæmatoxylin and eosin (Figs. 10, and 11, Sup. C.) The peripheral portion of these cells extends to the limiting membrane in a thick process nearly as wide as the cell in the region of the nucleus. The supporting cells in the olfactory region of the pig do not possess cilia. The central process is fine, frequently branched, or forked (Fig. 4), and extends to the basement membrane. Between the forks of the supporting cells are the basal cells in the same relative position as they are in the respiratory area. In no case, neither in the sectioned material nor in the macerated preparations, has a nerve fiber been seen in connection with a supporting cell.

Olfactory Region. (b) The Sensory Cells. The sensory elements 
of this region, isolated by maceration, are shown in Figs. 5, 6, 7, 8,9 , and in normal position in the membrane in Figs. 10,11, and 12. As these figures show, the olfactory cells are bi-polar elements, the large oval cell body, which contains a nucleus of nearly the same shape, giving rise to a central and a peripheral process. The olfactory cell bodies lie at varying levels in the epithelium below the plane of the nuclei of the supporting cells. In the lower half of the cell body is the large ellipsoidal nucleus which, with iron alum and hamatoxylin, does not stain quite so deeply as the nuclei of the supporting cells. The peripheral process arises from the tip of a conical mass of cytoplasm which makes up the upper half of the cell body. This process varies in length in different cells, depending of course upon the position of the cell body within the membrane. The diameter of the process varies from one-fifth to one-third that of the cell body, and extends to the surface and passes through the limiting membrane enlarging in this region into a knob $(K n$. $)$ whose diameter is one and one-half to two times that of the process itself. On this knob are to be seen four to eight hair-like processes, extending above the knob into the cavity of the nose. In both the macerated material and in the sections the olfactory hairs vary in length from .008 to $.001 \mathrm{~mm}$., or a trifle longer than the cilia of the supporting cells of the respiratory region. Unlike the latter they are thick and instead of being pointed are not only blunt but in some cases they seem to have more or less thickened ends. In the sections stained with iron alum and hæmatoxylin and in the macerated material stained with picro-carmine, the bases of these cilia, which are equatorially arranged around the knob of the process, are stained very deeply and look like small dots. It is possible to see olfactory hairs in all sections where the knobs are shown, but in the macerated material they do not occur so frequently and in a great many cases are broken off. Where these hairs do not show, however, the small dots representing the bases of them, can easily be seen. This absence of olfactory hairs from so many of the sensory elements in macerated material may be explained by the treatment which the cells received in being separated. I conclude that the olfactory hairs are normal structures and not artefacts. 
At different levels along the peripheral processes of the olfactory cells occur slight enlargements (Figs. 6, 7, 8). These show best in the isolated cells. As many as two have been seen on the same cell. Similar enlargements are shown in the figures of Max Schultze $(1856,1862)$ and in those of Von Brunn (1892).

Below the nucleus of the sensory cell the cytoplasm is drawn directly to a point which in the majority of the cells is in a line with the long central axis of the cell body, but sometimes it is found to one side of it. From this point emerges a long, slender, varicose fiber, (Cen. Pr.), which extends downward in a curved or wavy course toward the sub-mucosa passing between the feet of the supporting cells. It passes through the basement membrane into the sub-mucosa and there is lost in the connective tissue. In the sub-mucosa several of these fine fibers come together to form the smaller branches of the olfactory nerve, but the fibers do not anastomose. In the macerated preparations the cells possess only a very short fiber, and often none at all. By maceration, the central processes, like the olfactory hairs, are easily broken off.

In the sectioned material as well as in the macerated preparations have been seen oval cell bodies, possessing varicose nerve fibers like those of the sensory elements just described, but having no peripheral processes (Figs. 10, 11, 12). In the case of the sections it is plain that this appearance is due to the fact that the plane of the section does not pass through the peripheral process but only through the cell body. In Fig. 15A is shown the cell body of such an element and in Fig. 15B is shown the same region of the next section to it and in it is seen the peripheral process of the sensory cell (Per. Pr.), whose body in Fig. $15 \mathrm{~A}$ might be mistaken for a uni-polar element. Many similar cases have been examined and in all but a very few it was possible to find in the neighboring sections the missing peripheral processes. In like cases in the macerated material it could sometimes be seen that the process had been broken off in the maceration. There is not enough evidence from my observations to justify the separation of the sensory cells into the two classes of uni-polar and bi-polar elements. It appears that they are all bi-polar. 
The sub-mucosa of this region resembles that of the respiratory area except that it is much thicker and contains a greater number of Bowman's glands.

Fig. 9 shows the peripheral end of an olfactory cell broken away from its cell body and bearing eight olfactory hairs.

Figs. 10, 11 and 12 represent camera drawings of sections showing the various histological elements of the mucosa in their natural position. It is to be noted that the knob-like endings of the peripheral processes are situated in front of the limiting membrane. They are large and the olfactory hairs are long.

Fig. 13 shows a sensory cell in section with its nucleus near the basement membrane, and, consequently, a very long peripheral process.

The results obtained indicate the success of Zenker's fluid followed by iron hæmatoxylin staining. An examination of the published drawings of the histology of the nasal membrane will show that it is infrequent to find the knob-like eminences and the olfactory hairs so well exhibited as in the pig material upon which the above observations are based, The sketches that show the hairs best developed are those of Ballowitz ${ }^{12}$ in Petromyzon.

The Intermediate Zone. This zone lies between the two regions just described and exhibits the characteristics of each. It is the shading of the one into the other. It is thinner than the olfactory region, and thicker than the respiratory. Besides the sensory elements it possesses supporting cells of three types. Of the latter the basal cells are similar to those of the other two regions. The long supporting cells proper can be divided into two classes on the basis of possessing or lacking cilia. Those that do bear cilia (Fig. 14, Sup. C.- are very similar to the supporting elements of the respiratory area. They extend across the full width of the membrane and their central processes are pointed and rest upon the basement membrane. The other supporting elements lack cilia, and in this regard are like those of the olfactory region, but their central processes do not appear to be forked.

The sensory elements of this region are not as long as those

${ }^{12}$ Archir. f. Mik. Anat. Bd. 64, 1904. 
of the olfactory area, and are fewer in number. In the well differentiated olfactory region about 70 per cent of the cells appear to be nerve elements, while in the middle of the intermediate zone about the same percentage of the elements are supporting cells. The nerve cells of this zone become more and more scattered as the respiratory region is approached.

A differential count of the isolated cells from the entire turbinal membiane shows that 49 per cent are olfactory elements.

SUMMARY. The facts of observation briefly summarized are as follows:

1. The nasal mucous membrane of the pig is divided into three areas: The olfactory, characterized by the predominance of sensory cells; the respiratory region, characterized by the absence of sensory cells and the presence of ciliated supporting cells; and, third, the intermediate zone, characterized by the presence of a small number of sensory cells and both ciliated and unciliated supporting cells.

2. There are supporting cells of three easily distinguishable types, viz: the unciliated of the olfactory region; the ciliated of the respiratory region; and the basal cells common to the three regions. Besides these there are the ciliated cells of the intermediate region which differ slightly from those of the respiratory area, and also, the unciliated supporting elements of the intermediate zone which are not identical with those of the olfactory region.

3. The sensory cells so far as observed are of one type, bi-polar. The peripheral process is slender and on its free end is a knob bearing five to eight hair-like processes. The nerve fiber passing centrally, is fine and beset with varicosities. The fibers unite to make up the bundles of the olfactory nerve.

4. No connection has been observed between nerve fibers and the supporting elements of any area. 


\section{EXPLANATION OF FIGLRES}

Vig. 1. Section of the ethmo-turbinal folds of a pig embryo 12 inches long. The section is eut in a plane perpendicular to the long axis of the folds.

Fig. 2. Section through the respiratory region of the second turbinal fold of a pig 11 in. long. Bas. C., basal cell; Cil., Cilia; Cen. Pr., central process; Nu., nucleus; Sup. C., supporting cell.

Fig. 3. Isolated supporting cell of the respiratory region macerated in 25 per cent alcohol.

FIG. 4. Single supporting cell from the olfactory region of the pig. L. M., limiting membrane; $N u$, nuclcus; Cen. Pr., central process.

Figs. 5, 6, 7, 8. Sensory cells from the olfactory membrane of the pig drawn to the same scale. Showing variations in the length of the peripheral process. Cen. $P r$., central process or nerve fiber; $K n$., olfactory knob; $N u$., nucleus; Olf. $H$., olfactory hair, Per. Pr., peripheral process.

FIg. 9. Peripheral end of an olfactory cell bearing eight olfactory hairs.

Fig. 10. Section through the olfactory membrane of a pig embryo $6 \frac{2}{2}$ in. long. From the second ethmo-turbinal fold. Olf. $H$., olfactory hairs; $K n$., terminal knob of olfactory ccll; Olf. C., olfactory cell; Nu., nucleus; Cen. Pr., central process or nerve fiber; Bas. C., basal cell; Bas. Mem., basement membrane.

Fig. 11. Olfactory membrane of the lateral surface of the first ethmo-turbinal fold of a pig embryo $6 \frac{1}{2}$ in. long. Reference letters same as in Fig. 10.

Fig. 12. Olfactory membrane from the same specimen and the same fold as in Fig. 11; Lim. Mem., Limiting membrane.

FIG. 13. Section through the olfactory membrane of a pig embryo $6 \frac{1}{2}$ in. long, showing one olfactory cell with a very long peripheral process.

FIg. 14. Section of the olfactory membrane in the intermediate zone from the first ethmo-turbinal fold of a pig embryo $6 \frac{1}{2}$ in. long.

FIG. $15 \mathrm{~A}$. Section through the intermediate zone of the olfactory membrane from the first ethmo-turbinal fold of a pig embryo $6 \frac{1}{2}$ in. long.

Frg. $15 B$. Adjacent section to that shown in $A$. Shows the peripheral process of the chief olfactory cell the body of which is shown in the previous section. 


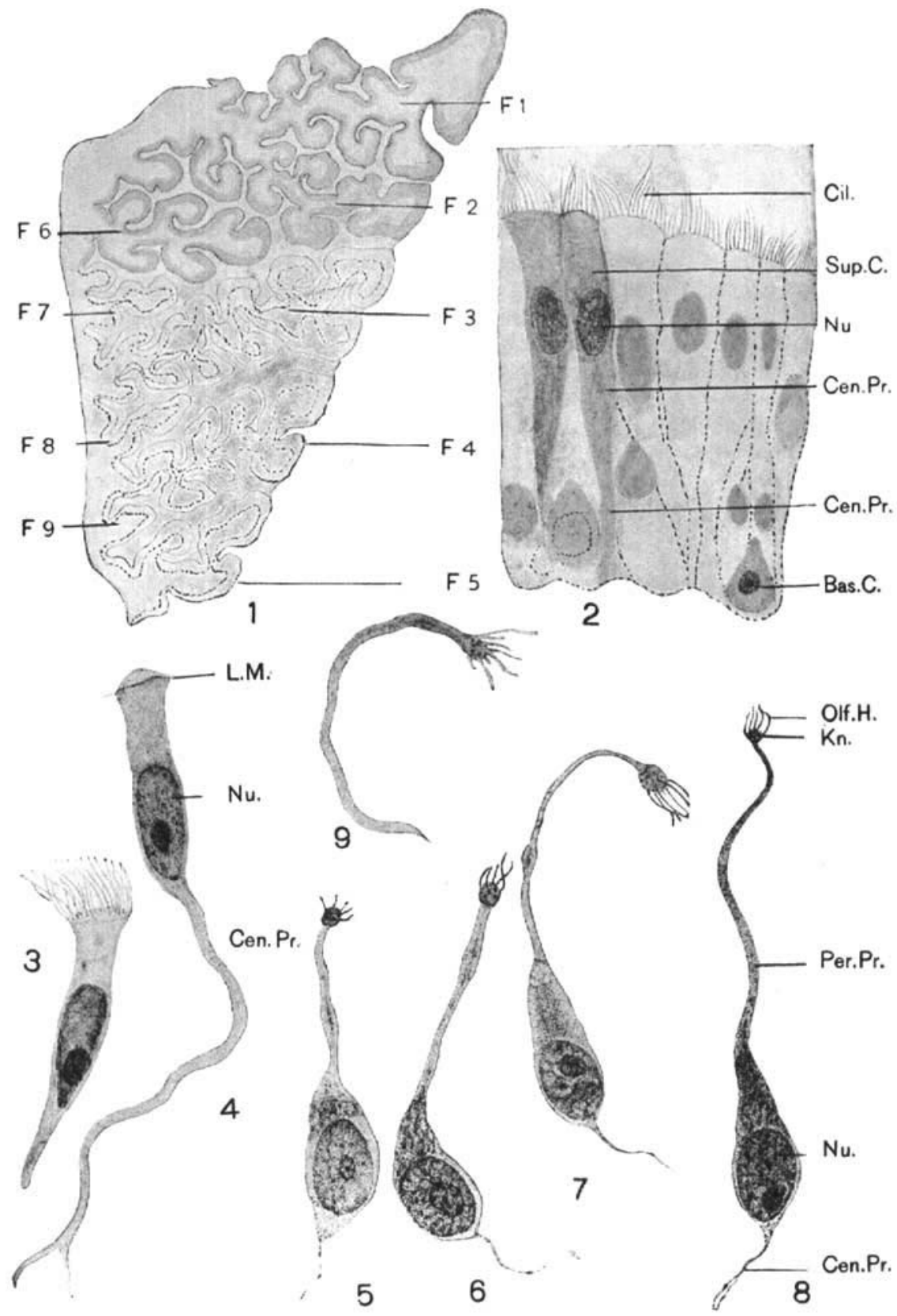



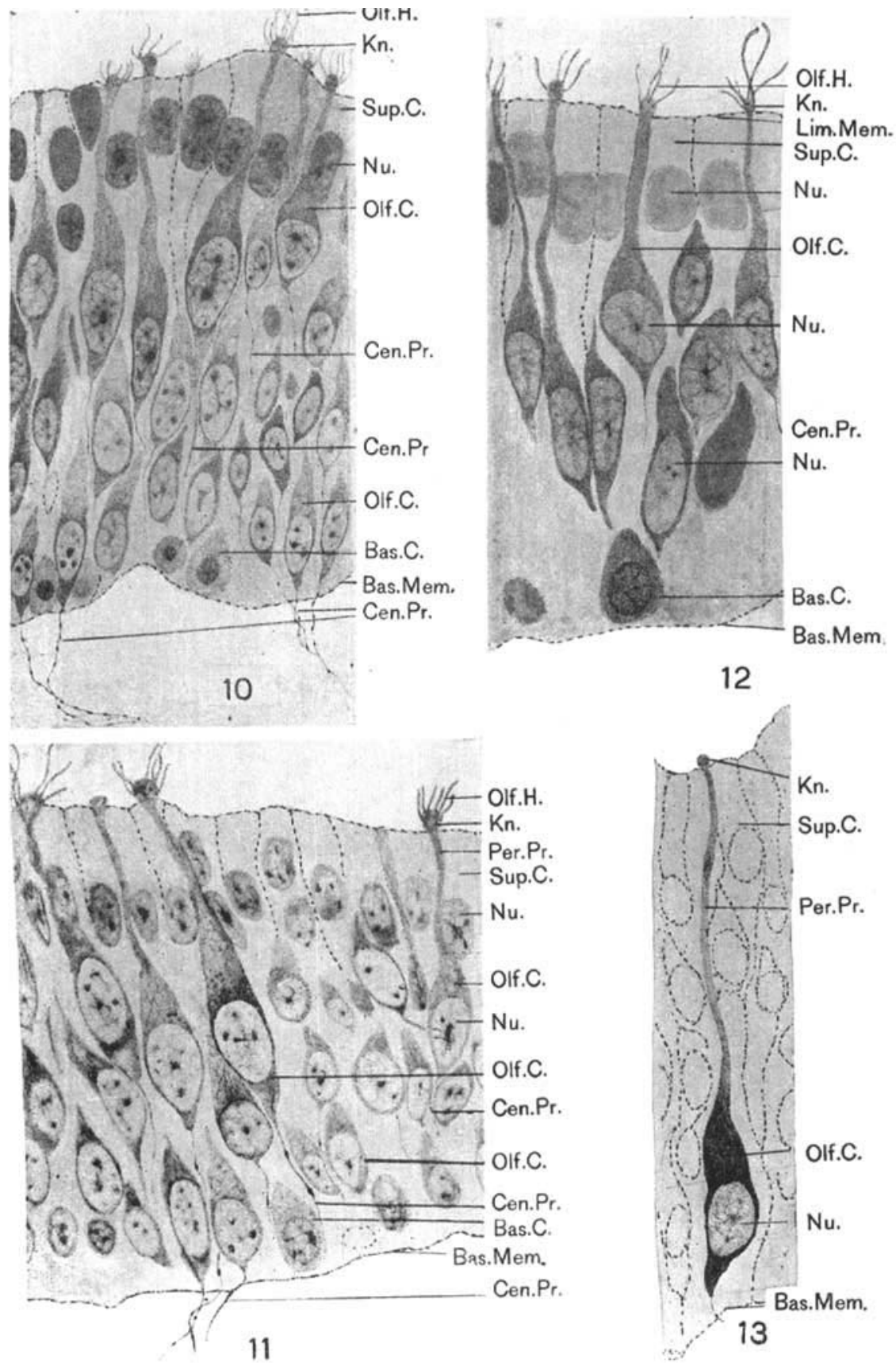


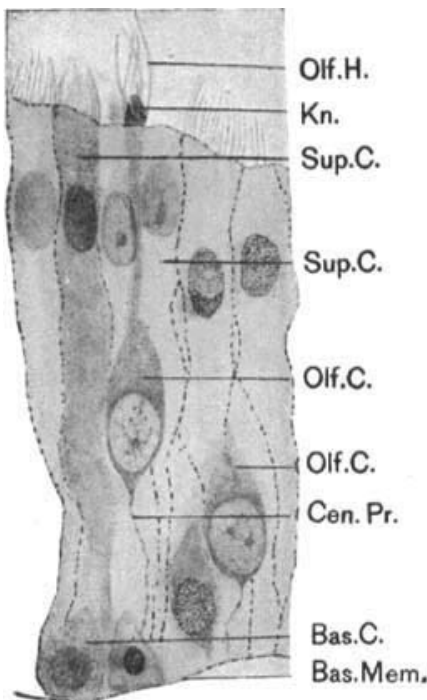

14

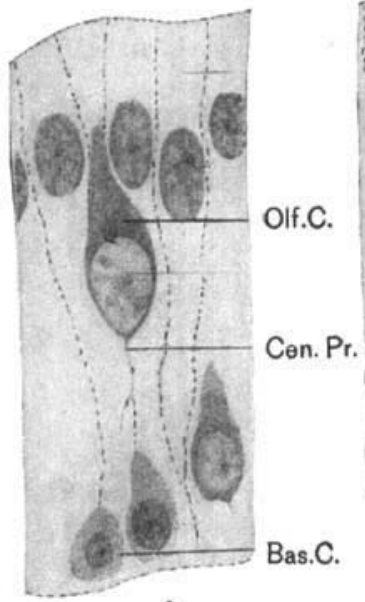

A

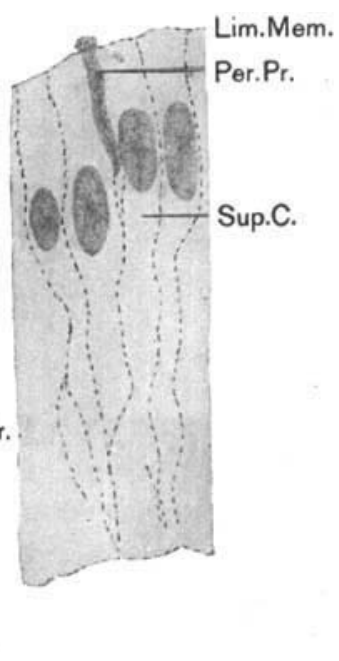

15 